\title{
A study of the small intestinal mucosa using the scanning electron microscope
}

\author{
M. N. MARSH AND J. A. SWIFT \\ From the Department of Medicine, Royal Postgraduate School of Medicine, London, and the Unilever Research \\ Laboratory, Isleworth, Middlesex
}

SUMMARY In this paper we describe the features of small intestinal structure in normal control subjects using the scanning electron microscope.

Rubin (Rubin, Brandborg, Phelps, and Taylor, 1960) first used the dissecting microscope to examine the mucosal surface of the small intestine, and in the following year Holmes, Hourihane, and Booth (1961 $a$ and b) demonstrated its diagnostic use when they described the characteristic surface changes in adult coeliac disease and tropical sprue. A flat mucosa, corresponding to the histological description 'subtotal villous atrophy', was invariably associated with gluten-induced enteropathy. A convoluted appearance of the jejunal mucosa, histologically corresponding to 'partial villous atrophy', was sometimes observed in adult coeliac disease, but was also seen in six cases of tropical sprue, of which one had similar changes in the ileal mucosa (Booth, Stewart, Holmes, and Brackenbury, 1962). Furthermore, it has been possible to make sequential comparisons between the degree of mucosal regeneration and recovery of absorptive function in individual patients treated with a gluten-free diet (Stewart, Pollock, Hoffbrand, Mollin, and Booth, 1967). Studies of this kind have widened our understanding of mucosal structure, but further advances have been limited by the low resolving power of the dissecting microscope. The development of a commercial scanning electron microscope has introduced a method of examining mucosal structure in greater detail than is possible with the binocular microscope (Marsh, Swift, and Williams, 1968).

\section{THE SCANNING ELECTRON MICROSCOPE}

The principle of this instrument is shown in Figure 1. A beam of high-energy electrons, accelerated from a heated hairpin tungsten filament under a potential of $20 \mathrm{kV}$, is focused into a narrow probe the diameter of which may be varied by means of two electromagnetic lenses ( 1 and 2$)$; a third electromagnetic lens is used to focus the electron probe onto the specimen (3). The probe is scanned in a raster about the specimen surface by means of scanning coils located in the third electromagnetic lens.

Secondary low-energy electrons emitted by the

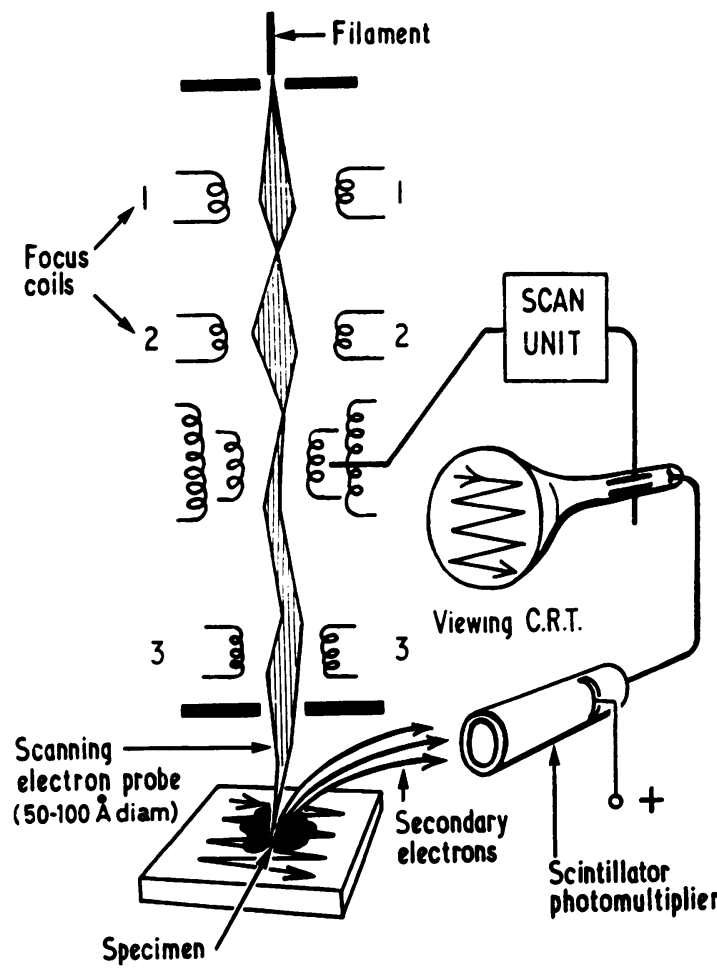

FIG. 1. High-energy electrons, drawn off a tungsten filament at $20 \mathrm{kV}$, are focused into a probe 50 to $100 \mathrm{~A}$ diameter by three electromagnetic lenses. Low-energy electrons emitted by the specimen are attracted into a scintillator-photomultiplier, which modulates the intensity of the light spot seen on the television viewing screen of a cathode ray tube (CRT). A scanning unit causes the probe and spot to describe zig-zag rasters in synchrony. 
specimen are attracted towards a positively charged Faraday cage and after passing through a wire gauze at the surface of the cage are further accelerated by an applied potential difference of $10 \mathrm{kV}$ before striking an aluminium-coated plastic scintillator. The light generated at the scintillator passes down a Perspex light guide into a photomultiplier which amplifies the signal. This signal is used to modulate the brightness of a light spot scanning the screen of a television display tube in synchrony with the raster described by the examining probe. The images produced in this way are related to the surface topography of the specimen under observation. Changes in magnification are made by varying the area of the specimen scanned by the electron probe. (For detailed analysis see Hayes and Pease, 1968.)

In this paper we describe in detail the appearances of the normal human small-intestinal mucosa seen in this instrument.

\section{METHODS}

Specimens of fresh jejunal mucosa were obtained from subjects undergoing operative treatment for peptic ulceration or carcinoma of the pancreas. Other specimens were obtained with a suction capsule (Crosby and Kugler, 1957) from patients admitted to a general medical ward for investigation of malabsorption. Disease of the small intestine was excluded in all patients.

The specimens were oriented, pinned out, and fixed for four hours in $5 \%$ glutaraldehyde, buffered to $p \mathrm{H} \mathrm{7.3}$ with $0 \cdot 1 \mathrm{M}$ phosphate. During this procedure the mucosa was viewed through a light binocular microscope and cleaned with a fine, camel-hair brush. After fixation the specimen was placed in $0.1 \mathrm{M}$ phosphate buffer with sucrose at $4^{\circ} \mathrm{C}$ in which it could be stored for several days. Immediately before being submitted to scanning electron microscopy the specimens were washed in three changes of distilled water at $4^{\circ} \mathrm{C}$ over an eight-hour period. They were subsequently transferred to the previously cooled stage of a Speedivac-Pearse vacuum tissue drier and freeze-dried at $-50^{\circ} \mathrm{C}$ for 18 hours. Dried tissue was kept in clean glass bottles over anhydrous calcium chloride. The specimens were attached to individual aluminium mounting stubs $(12 \mathrm{~mm}$ diameter) with Durofix adhesive and placed in an Edwards 12 E6 vacuum coating unit. They were rapidly rotated while being coated with a layer of carbon (100 $\AA$ thick) and a layer of metallic silver ( $500 \AA$ thick). The coated specimens were examined directly in a Stereoscan mk II (Cambridge Instrument Co.) scanning electron microscope operated at an accelerating potential of $20 \mathrm{kV}$. Photographs of the specimens were recorded on the 1,000 line television display tube of the microscope using Ilford FP4 $35 \mathrm{~mm}$ film. It was possible to resolve to $100 \AA$ by using a clean, 300 micron aperture, by making frequent corrections to the astigmatism of the condenser lens system, and by using sufficiently high condenser lens currents to achieve the smallest probe diameter consistent with reasonable levels of noise in the TV display circuit of the microscope (Swift and Marsh, 1968).

\section{RESULTS}

At low magnifications $(\times 20$ to $\times 100)$ the prepared mucosal surface is similar to that seen through the diusecting microscope. Because of the high depth of focus of the scanning electron microscope, all parts of the specimen are sharply in focus, the villi being well contrasted and distinct from each other (Fig. 2). It is easy and convenient to scan large pieces of tissue $\left(10 \mathrm{~mm}^{2}\right)$ at this magnification in order to gain a clear, detailed impression of the overall villous pattern. Furthermore, it is possible to select individual villi for closer observation at higher magnifications.

Within the range of magnifications $(\times 100$ to $\times 5,000$ ) the individual villi can be resolved. Fingershaped villi have broad bases tapering to blunt points, and are between 0.1 and $0.25 \mathrm{~mm}$ across. There is marked variation in shape, some being circular in cross section while others are flattened and tongueshaped (Figs. 2 and 3). Leaved villi are seen in most mucosae; in some they form the predominant surface pattern while in others they are few. Many leaves give the specimen a 'ridged' appearance (Fig. 4). These variations in villous structure illustrate the wide normal range.

Crypt orifices may be seen to open around the bases of the villi, but may be shown more clearly by displacing the villi in one area of the specimen before fixation has occurred. The orifices are numerous and greatly exceed the villi with which they are related (Figs. 3 and 5). They measure 100 microns or more across, open abruptly onto the surface and contain amorphous material.

A marked feature of the villus is its corrugated surface, which is not easily seen in the dissecting microscope. The corrugations are deep, irregular clefts cutting into the side of the villus and dividing it into separate islands of tissue (Fig. 6). The majority of these corrugations tend to run in a horizontal direction, giving the fir-tree outline of villi seen in histological sections (Fig. 7). The corrugations end abruptly and do not form a continuous system of clefts.

Occasionally circular or oval holes are seen opening directly into these clefts or into shallow troughs on the surface. These holes are goblet cell orifices and are 3 to 8 microns in diameter at the surface. The differences in outline and in size of the orifices of the goblet cells are striking and may represent various stages in the secretion of mucus (Fig. 7). Many goblet cells are empty but the openings are fenestrated by membranes still adherent 

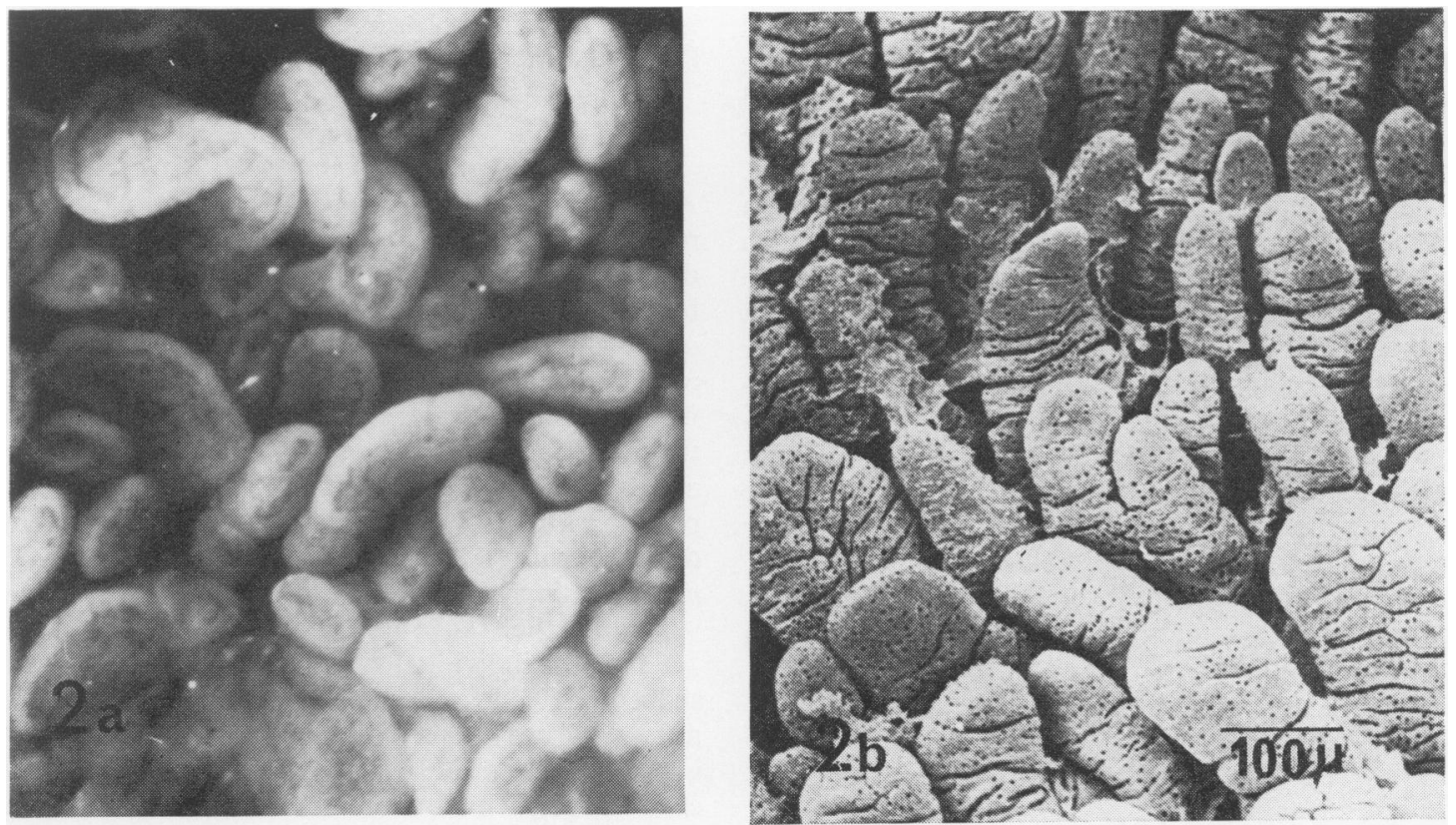

FIGS. $2 \mathrm{a}$ and $2 \mathrm{~b}$. Comparison between the appearance of villi seen $(\mathrm{a})$ in the dissecting microscope $(\times 50)$ and $(\mathrm{b})$ in the scanning electron microscope $(\times 50)$. Note contrast and clarity of detail in (b).
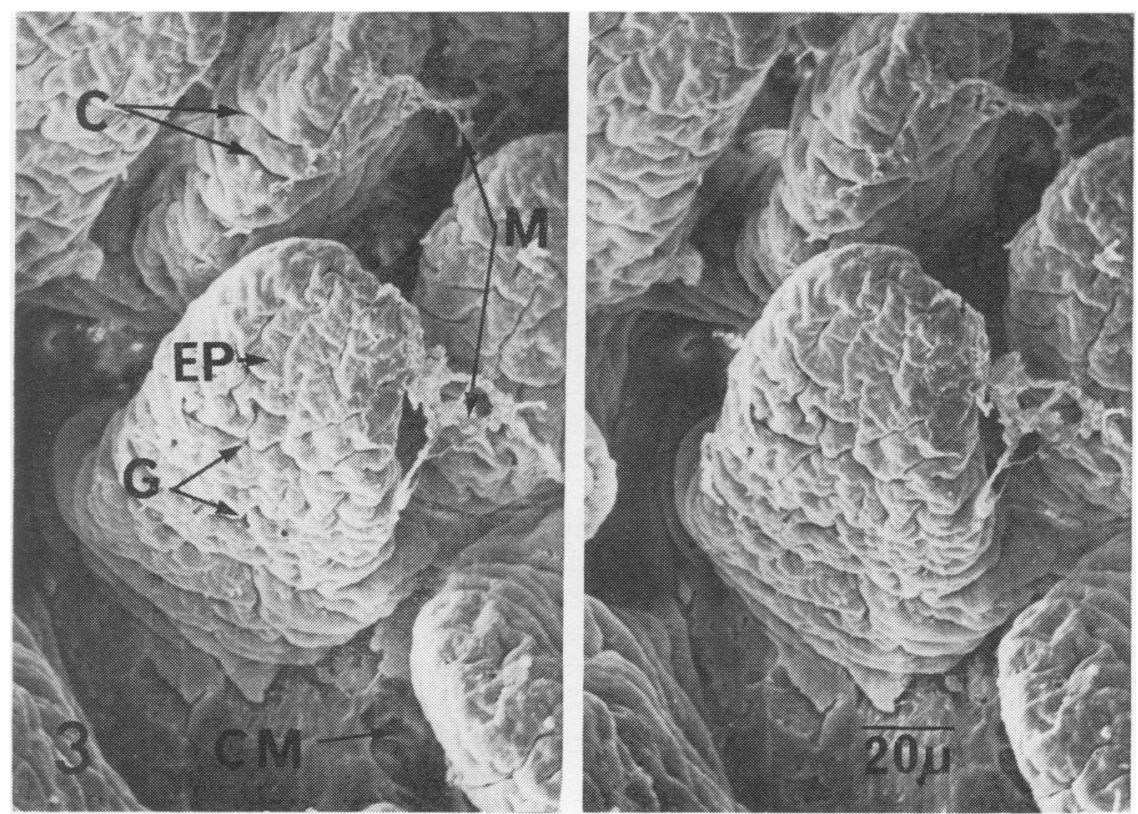

FIG. 3. Stereo-pair scanning micrographs showing a group of villi. The great depth of focus of the scanning electron microscope is clearly demonstrated. Epithelial cells, EP, goblet cell orifices, $G$, corrugations, C, crypt mouths, CM, and mucus, $M$. 

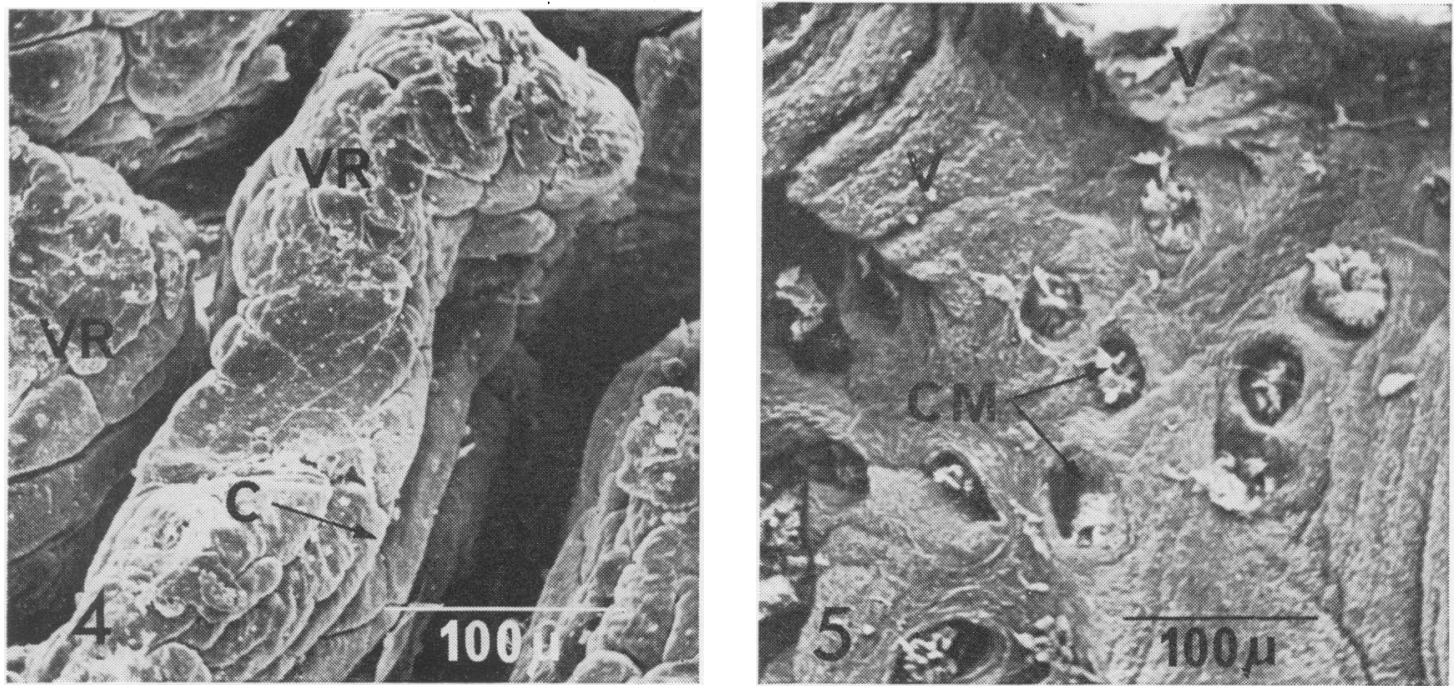

FIG. 4. Mucosal specimen showing well-defined 'ridged' villi VR. Corrugations $C$ run horizontally.

FIG. 5. Normal mucosa. The villi, $V$, were displaced during fixation to reveal numerous crypt mouths, $C M$, containing amorphous material.

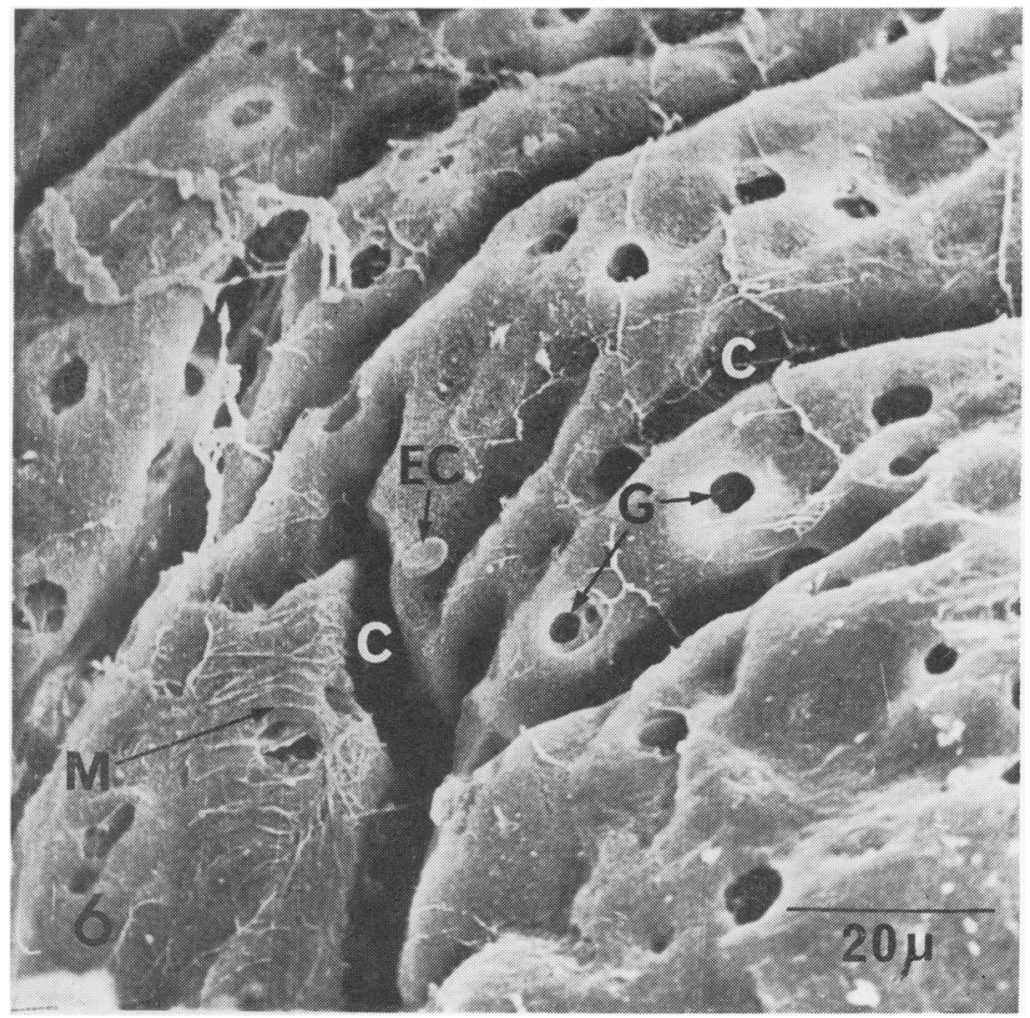

FIG. 6. Detail from the side of a villus illustrating the depth and tortuosity of corrugations $C$, goblet cell orifices $G$, and strands of surface mucus $M$. Occasionally red blood cells, $E C$, are seen on the villous surface. 

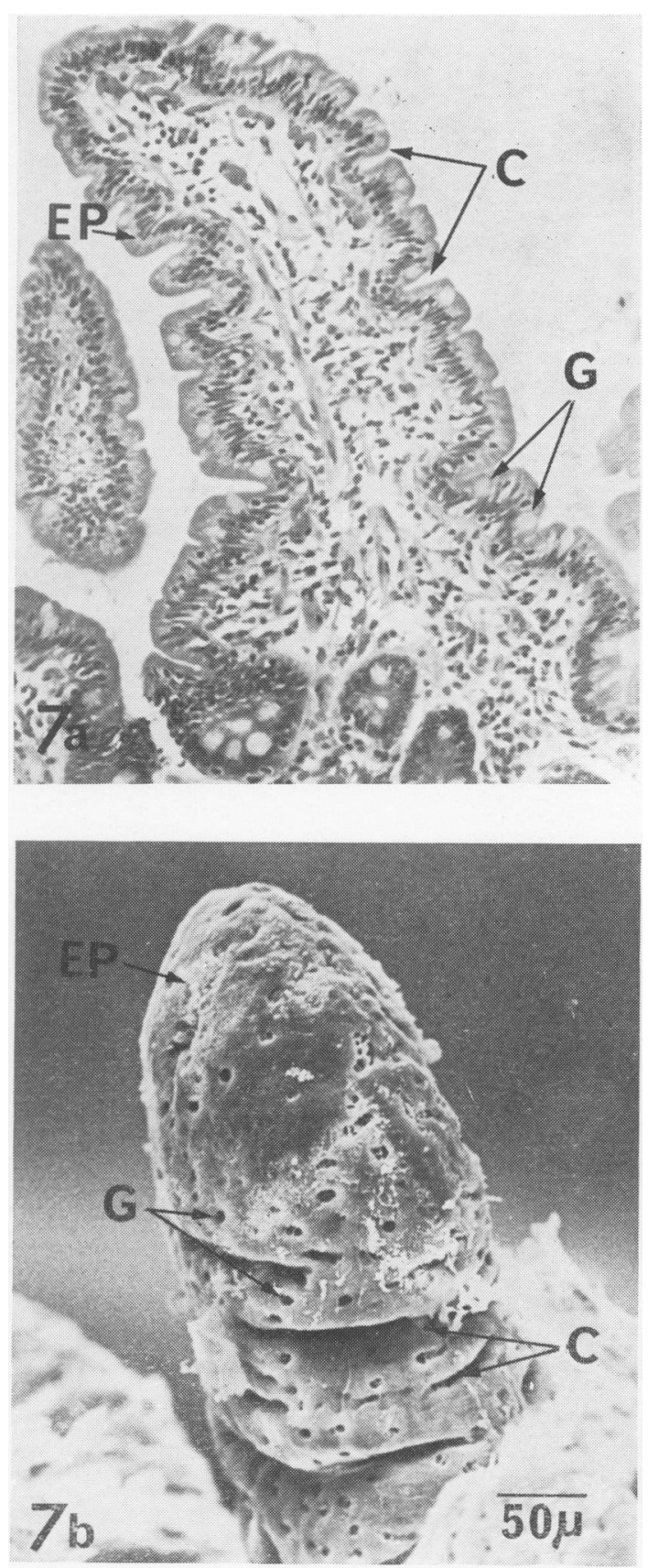

FIGs. 7a and 7b. A villus as seen (a) in histological section $(\times 200)$ and (b) by scanning electron microscopy $(\times 200)$. The surface corrugations $C$, epithelial cells EP, and goblet cell orifices $G$, may be compared directly. These appearances should be compared with those shown in Figures 6, 8 , and 9 .

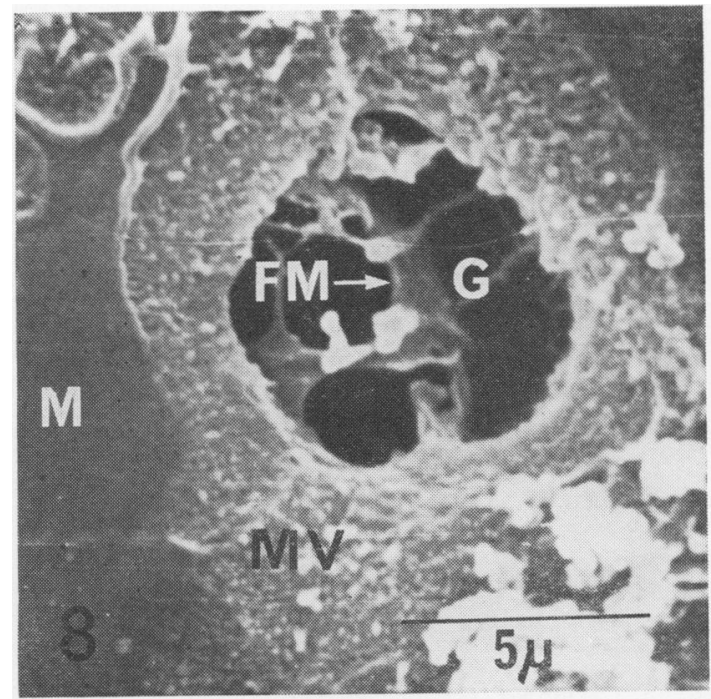

FIG. 8. Higher magnification of goblet cell orifice $G$, showing fenestrated membrane FM, extending deeply into underlying 'goblet'. Mucus $M$, and microvilli $M V$.

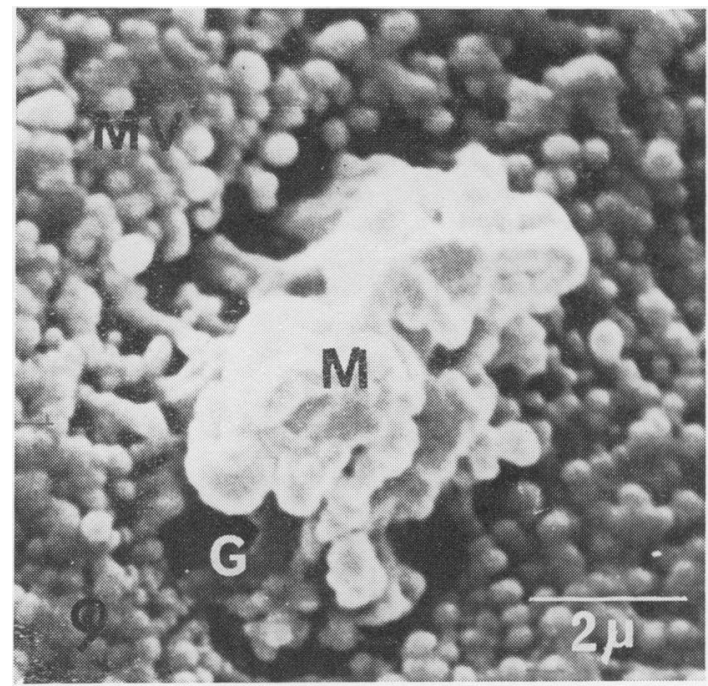

FIG. 9. Goblet cell $G$, discharging mucus M. Microvilli $M V$. 


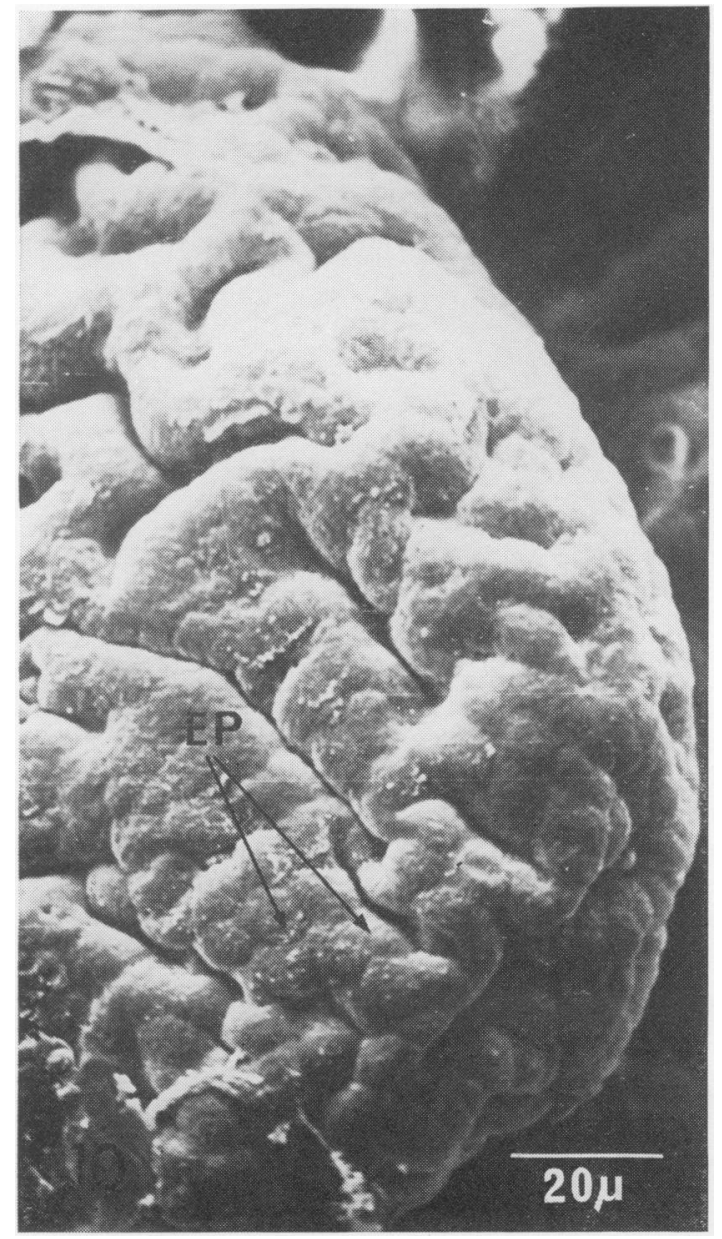

FIG. 10. Villous tip. Detail showing hexagonal arrangement of epithelial cells EP.

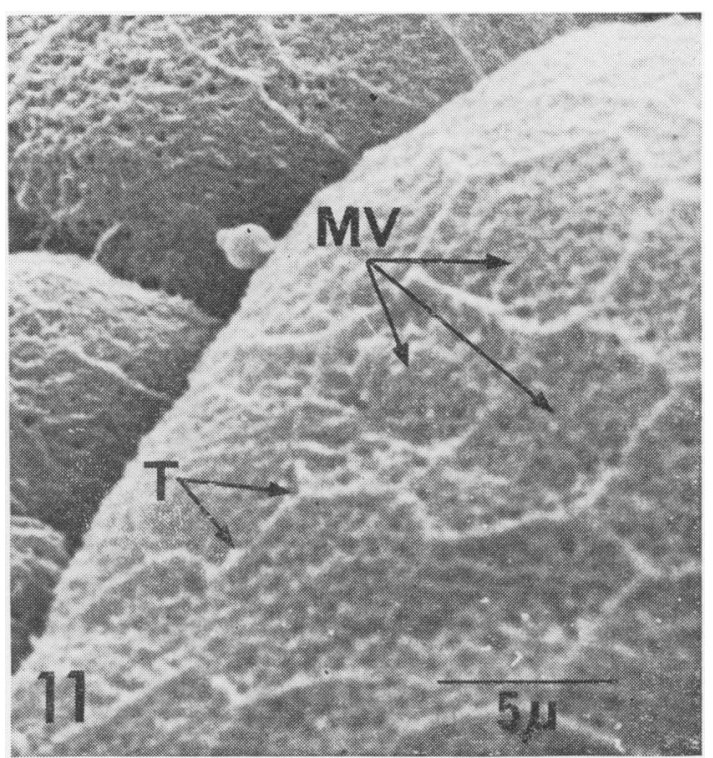

FIG. 11. Preparative artefact showing exaggerated cell outlines. The tight junctions, $T$, seem to have remained in place but in between cytoplasm has contracted, leaving the microvilli, $M V$, level with villous surfaces.

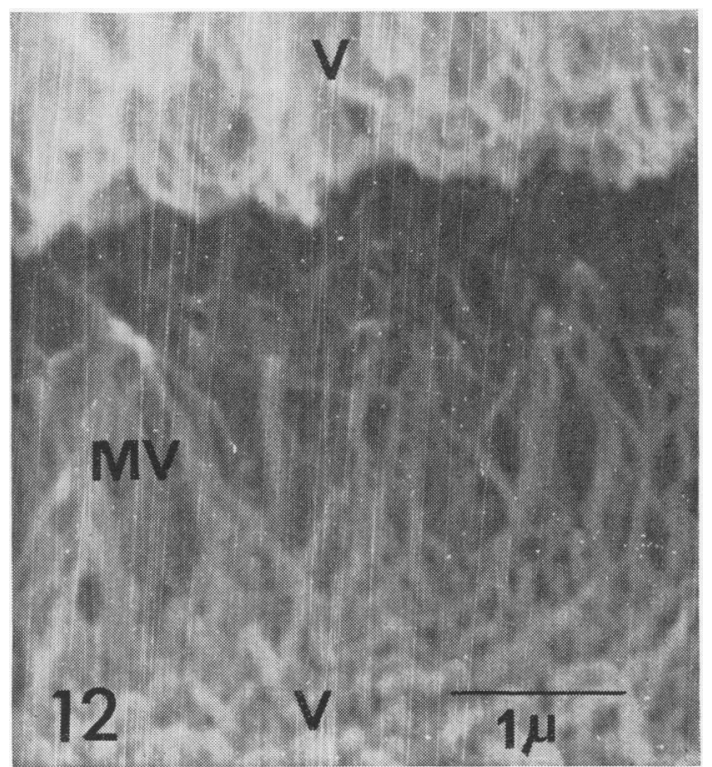

FIG. 12. Area between two villi, $V$, at high magnification, showing filamentous microvilli, $M V$, projecting into lumen. 


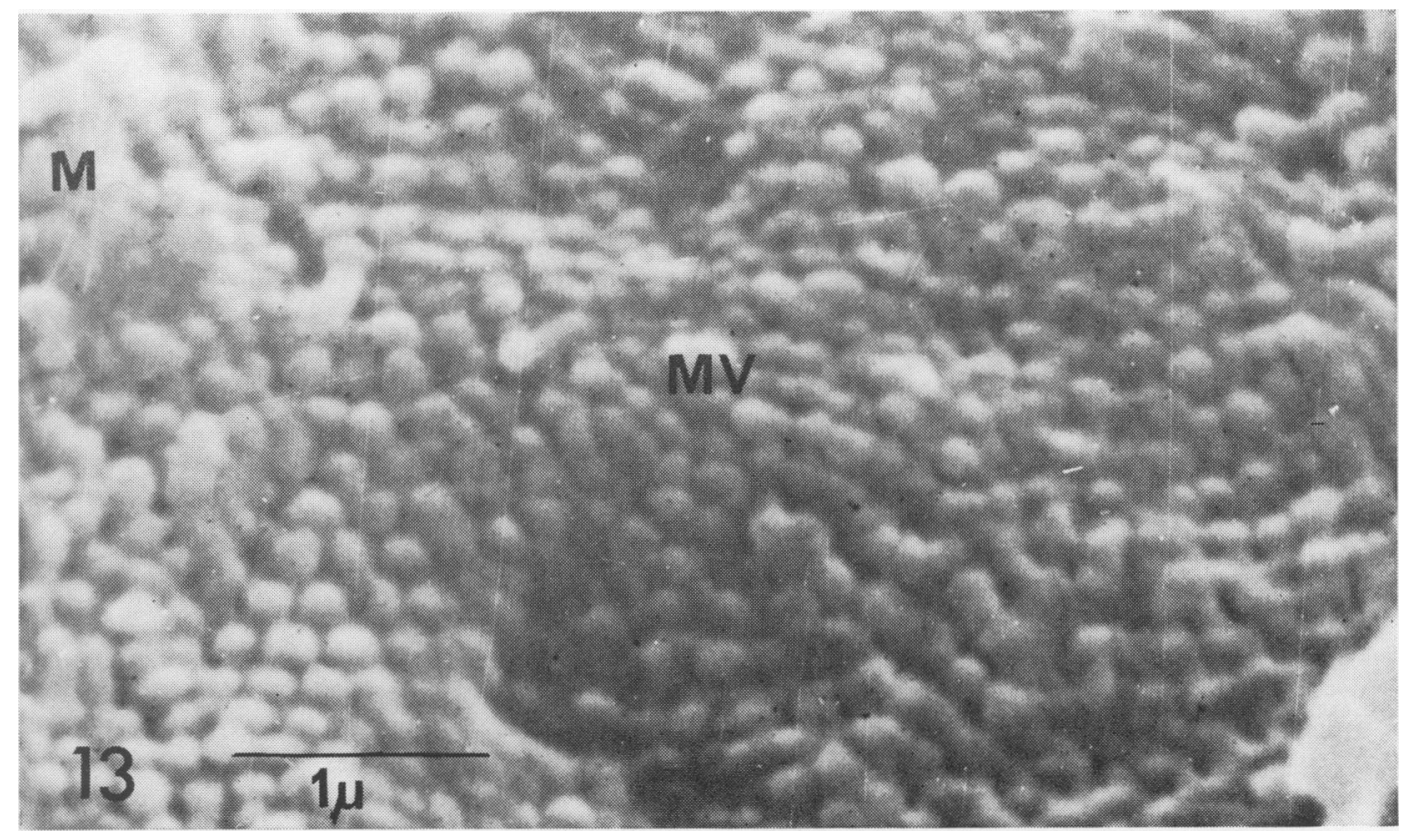

FIG. 13. Tips of rod-shaped microvilli, $M V$, and mucus $M$.

to the interior surface of the underlying goblet (Fig. 8). In other preparations irregular blobs of mucus extruding from goblet cells are seen extending above the microvilli of adjacent epithelial cells (Fig. 9).

At similar magnifications the outlines of individual epithelial cells are sometimes seen. They are flattopped or gently convex outwards and hexagonal in outline, their packing giving rise to a honeycomb appearance on the villous surface (Fig. 10). The hexagonal packing is shown in greater detail in a specimen which appears to have shrunk so producing artefacts (Fig. 11). The cells appear to vary in size and the surface area can be calculated by estimating the mean cell diameter and assuming the outline to be circular (Table I). Mean cell diameter was found to lie between 7.2 and 7.9 microns, with a calculated mean surface area between 40 and 48 square microns.

At higher instrumental magnifications microvilli can be resolved. These appear as discrete structures giving the cell surface a granular or feathery texture at a magnification between $\times 5,000$ and 10,000 (Figs. 9 to 12). At higher magnifications $(\times 20,000)$ microvilli are seen as rod-shaped structures separated from each other by spaces of the order of 0.01 to 0.02 microns (Fig. 13). The diameters of microvilli are between 0.1 and 0.2 microns and thus there appear to be between 3,000 and 6,500 microvilli per epithelial cell (Table I).

Some uncleaned specimens illustrate mucus closely applied to the mucosal surface (Fig. 14) and entangling the microvilli. From these observations, however, it is impossible to distinguish clearly between mucus and the 'fuzzy coat' (Ito, 1965). It is possible that the latter is responsible for the icingsugar appearance of the surface of the mucosa in some areas (Fig. 15).

TABLE I

\begin{tabular}{|c|c|c|c|}
\hline \multirow[b]{2}{*}{$\begin{array}{l}\text { Number of } \\
\text { Cells } \\
\text { Counted }\end{array}$} & \multicolumn{3}{|c|}{ EPITHELIAL CELL DIMENSIONS } \\
\hline & $\begin{array}{l}\text { Measured } \\
\text { Epithelial Cell } \\
\text { Diameter }(\mu) \\
(\text { Mean } \pm 2 S D)\end{array}$ & $\begin{array}{l}\text { Calculated } \\
\text { Surface Area } \\
\left(\mu^{2}\right) \\
(\text { Mean } \pm 2 S D)\end{array}$ & $\begin{array}{l}\text { Estimated Micro- } \\
\text { villous Density } \\
\text { per Cell }\end{array}$ \\
\hline $\begin{array}{l}15 \\
27 \\
12 \\
17\end{array}$ & $\begin{array}{l}7 \cdot 2 \pm 1 \cdot 2 \\
7.9 \pm 1.4 \\
7 \cdot 6 \pm 1.6 \\
7 \cdot 4 \pm 1 \cdot 2\end{array}$ & $\begin{array}{l}40 \pm 12 \\
48 \pm 17 \\
45 \pm 18 \\
42 \pm 13\end{array}$ & $\begin{array}{l}2800 \text { to } 5200 \\
3100 \text { to } 6500 \\
2700 \text { to } 6300 \\
2900 \text { to } 5500\end{array}$ \\
\hline
\end{tabular}

\section{DISCUSSION}

In this study the scanning electron microscope has been used to examine the surface of human small intestinal mucosa. We record certain appearances which have not been described before with other microscopic techniques. The conventional way of examining the mucosal surface is limited by the lower resolving power and depth of focus of the dissecting microscope. Although it is possible to observe details of surface topography by examining ultrathin serial sections in the transmission electron 


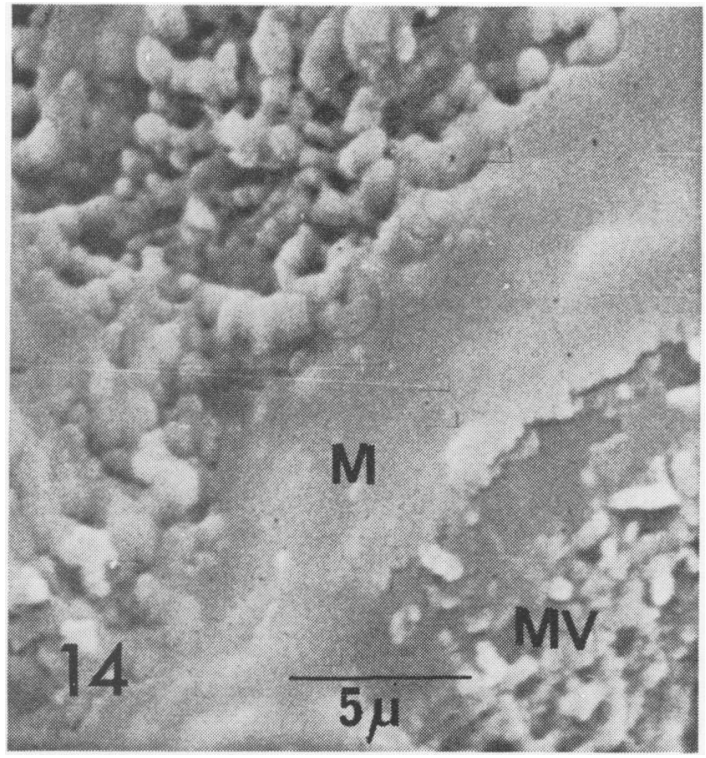

FIG. 14. Uncleaned specimen illustrating the matting of microvilli $M V$, by a thick layer of surface mucus $M$.

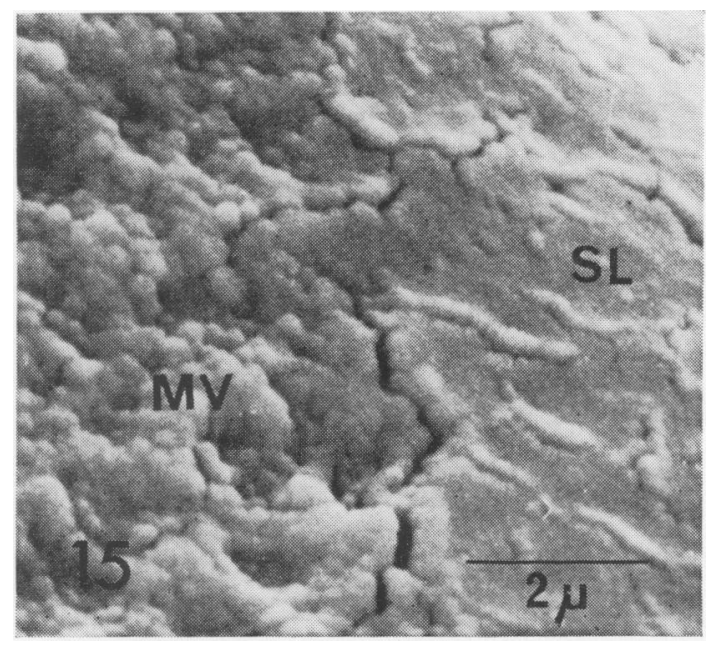

FIG. 15. Appearance of surface layer SL ?mucus, ?'fuzzy coat' to right of figure, obscuring microvilii. Microvilli $M V$, clearly visible on the left.

microscope, this is an excessiveiy difficult and timeconsuming technique compared with scanning electron microscopy.

Observations with the scanning electron microscope confirm the deductions of others that crypts greatly outnumber villi. There is no one-to-one relationship (Fig. 5), although histological sections give this impression. As many as 20 crypts may surround each villus (Cocco, Dohrmann, and
Hendrix, 1966), but a functional ratio of three crypts to one villus has been proposed (Loehry and Creamer, 1969). Clearly several crypts must supply a single villus with cells, and although there is no direct evidence, progression from crypts to villous tip may occur by a spiral movement around the villus. In this study there was no good evidence of cell extrusion at the villous tips, perhaps because of artefacts produced by cleaning and fixation. Alternatively extrusion may occur only at times when several degenerate cells have collected at the villous tip. In another study in which the opened jejunum of anaesthetized dogs was directly observed, it was concluded that villous cell loss is an intermittent phenomenon (Creamer, Shorter, and Bamforth,1961).

There is little information concerning the nature of the material which fills the lumen of the crypts. It probably consists of secretions from goblet cells, Paneth cells, and the 'undifferentiated' crypt cells, shown by Trier to secrete vesicles in response to pilocarpine (Trier, 1963).

It is possible to see epithelial cell outlines with the scanning electron microscope used at low magnification. It has also been possible to measure cell dimensions, and thus calculate a range for surface area and microvillous density per cell. There are several errors inherent in making these measurements. Fixation and drying probably cause some shrinkage of cells and it is difficult to ensure that each cell is scanned en face because of the natural curvature of the villous surface. More accurate measurements may be obtained by using stereo-pair scanning electron micrographs. True spatial coordinates can then be determined by analysing the pairs in a stereo viewing apparatus. In this study, however, each cell was assumed to be circular in cross-sectional area and the diameter of the surface of a cell was estimated from the mean of two measurements made at right angles to each other. Despite the obvious shortcomings of this method, the results of these measurements are included to provide information which is extremely difficult to obtain by any other method. Thus with the transmission electron microscope there is no certainty that an ultrathin section of a cell lies across a diameter, so that any calculations, eg, relating to variations in cell size or surface area based on the measured width of any sectioned cell, may be too low and therefore invalid.

In studies of normal human intestine using the transmission electron microscope, 4 microns has been taken to represent cell width (Ashworth, Chears, Sanders, and Pearce, 1961) and $16 \mu^{2}$ the free surface area of the epithelial cells, assuming that the luminal face is square. Brown (1962) in his study of human microvilli took $15 \mu^{2}$ as the free 
surface area of the epithelial cells, a figure originally derived by Granger and Baker (1950) in studies of rat mucosa. It would therefore seem reasonable to make other comparative measurements of large numbers of cells, both in normal and abnormal mucosae.

It is generally agreed that microvilli are 1 micron in length and $0 \cdot 1$ microns in diameter. We have observed microvilli of this diameter in preparations devoid of surface coating, but in other areas their diameter is larger, of the order of 0.2 micron. This increase in size could be due to a thin coating of mucus or condensed 'fuzzy coat'; it might also be due to the carbon and silver deposited onto the specimen during preparation. Assuming a microvillous diameter and interspace of 0.1 and 0.015 microns respectively, and using the calculated surface areas, the microvillous density per epithelial cell would lie between 3,000 and 6,500. Calculations reported in the literature range between about 2,000 and 3,000 per cell (Granger and Baker, 1950; Ashworth et al, 1961; Palay and Karlin, 1959; Brown, 1962). These figures are lower than those reported here because of much smaller estimates of cell diameter and hence of free surface area. Lastly, it has been possible to calculate that approximately 85 microvilli cover one square micron of cell surface, and that the surface of any epithelial cell is increased by a factor of $\mathbf{3 0}$ when covered by microvilli.

The undischarged goblet cell has a luminal plasma membrane covered by microvilli (Florey, 1960; Trier, 1963). As mucigen granules accumulate and enlarge, this membrane becomes thinner and the miciovilli smaller, fatter, and more disorganized (Florey, 1960; Bierring, 1962; Freeman, 1962). It is therefore difficult to recognize undischarged goblet cells with the scanning electron microscope because their luminal surfaces merge with those of adjacent epithelial cells; moreover their surface area in this phase of the secretory cycle may be quite small. Neither have we seen signs of impending discharge, $i e$, attenuation of microvilli, ballooning of the plasma membrane, or breaks in its continuity.

The frequent finding of fenestrated ostia implies that mucus is extruded from the cell unattached to its Golgi-derived membrane. This membrane appears to remain inside the apical portion of the empty goblet after discharge, a finding also noted by Trier (1963). These observations are consistent with the view that mucus is discharged by merocrine secretion, a process in which no external loss of cell membrane occurs. The state of the goblet cell at the moment of fixation is also dependent on many other factors, $e g$, mechanical and traumatic (Moe, 1955), degenerative (Padykula, 1962), and, in the case of our operative specimens, by fasting and the drugs used for anaesthesia.
A 'fuzzy coat' layer immediately adjacent to the plasma membrane of the lining cells of the gastrointestinal tract was reported in 1965 (Ito, 1965). This coating contains polysaccharide and looks amor phous in the transmission electron microscope: its thickness varies from cell to cell (Ito, 1965; Mukherjee and Williams, 1967). It is resistant to chemical and enzyme activity, suggesting that it is part of the epithelial cell and probably synthesized by it. It thus creates a special micro environment between the intestinal lumen and the cell interior.

In our studies we have frequently observed a layer of material coating the surface of the mucosa and obscuring the underlying cellular detail, particularly at magnifications above $\times 10,000$. Despite the most careful cleaning of the specimen this material is apparent in most specimens. With the scanning electron microscope it is not possible to say whether the layer we observed is mucus or 'fuzz' (Fig. 15). The technical problems involved in cross-checking these appearances in the transmission electron microscope on the same piece of tissue makes interpretation difficult. Yet it is evident that scanning electron microscopy could be useful in defining the surface morphology and distribution of this coating.

We are grateful to Professor C. C. Booth and Dr G. Neale for their encouragement and criticisms: they also allowed us to study their patients.

Our thanks are due to Mr Alan G. Cox, and Mr J. Spencer, for their cooperation in allowing us to have pieces of mucosa from resected intestinal specimens.

Dr A.C. Brown, of Unilever Research, was kind enough to examine some of our material in the scanning electron microscope.

\section{REFERENCES}

Ashworth, C. T., Chears, W. C., Sanders, E., and Pearce, M. B. (1961). Non-tropical sprue. Arch. Path., 71, 13-19.

Bierring, F. (1962). Electronmicroscopic observations on the mucus production in human and rat intestinal goblet cells. Acta path. microbiol. Scand., 54, 241-252.

Booth, C. C., Stewart, J. S., Holmes, R., and Brackenbury, W. (1962). Dissecting microscope appearances of intestinal mucosa. (Ciba Foundation Study Group No. 14): In Intestinal Biopsy, edited by G. E. W. Wolstenholme and M. P. Cameron, pp. 2-23. Churchill, London.

Brown, A. L. (1962). Microvilli of the human jejunal epithelial cell. J. Cell. Biol., 12, 623-627.

Cocco, A. E., Dohrmann, M. J., and Hendrix, T. R. (1966). Reconstruction of normal jejunal biopsies: three-dimensional histology. Gastroenterology, 51, 24-31.

Creamer, B., Shorter, R. G., and Bamforth, J. (1961). The turnover and shedding of epithelial cells. Part 2: The shedding in the small intestine. Gut, 2, 117-118.

Crosby, W. H., and Kugler, H. W. (1957). Intraluminal biopsy of the small intestine. Amer. J. dig. Dis., 2, 236-241.

Florey, H. W. (1960). Electron Microscopic observations on goblet cells of the rat's colon. Quart. J. exp. Physiol., 45, 329-336.

(1962). The secretion and function of intestinal mucus. Gastroenterology, 43, 326-329.

Freeman, J. (1962). Fine structure of the goblet cell mucous secretory process. Anat. Rec., 144, 341-358. 
Granger, B., and Baker, R. F. (1950). Electron microscope investigation of the striated border of intestinal epithelium. Anat. Rec., 107, 423-441.

Hayes, T. L., and Pease, R. F. W. (1968). The scanning electron microscope: principle and applications in biology and medicine. Advanc. biol. med. Phys., 12, 85-137.

Holmes, R., Hourihane, D. O'B., and Booth, C. C. (1961a). Dissecting microscope appearances of jejunal biopsy specimens from patients with 'idiopathic steatorrhoea'. Lancet, 1, 81-83.

$-1,-,(1961 \mathrm{~b})$. The mucosa of the small intestine. Postgrad. med. J., 37, 717-724.

Ito, S. (1965). The enteric surface coat on cat intestinal microvilli. J. Cell. Biol., 27, 475-491.

Loehry, C. A., and Creamer, B. (1969). Three-dimensional structure of the small intestinal mucosa in health and disease. Gut, 10 6-12.

Marsh, M. N., Swift, J. A., and Williams, E. D. (1968). Studies of small intestinal mucosa with the scanning electron microscope. Brit. med. J., 4, 95-96.

Moe, H. (1955). On goblet cells, especially of the intestine of some mammalian species. Int. Rev. Cytol., 4, 299-334.
Mukherjee, T. M., and Williams, W. A. (1967). A comparative study of the ultrastructure microvilli in the epithelium of small and large intestine of mice. J. Cell Biol., 34, 447-461.

Padykula, H. A. (1962). Recent functional interpretations of intestinal morphology. Fed. Proc., 21, 873-879.

Palay, S. L., and Karlin, L. J. (1959). An electron microscopic study of the intestinal villus: 1 -The fasting animal. $J$. biophys. biochem. Cytol., 5, 363-372.

Rubin, C. E., Brandborg, L. L., Phelps, F. C., and Taylor, H. C. (1960). The apparent identical and specific nature of the duodenal and proximal jejunal lesion in coeliac disease and idiopathic steatorrhea. Gastroenterology, 38, 28-49.

Stewart, J. S., Pollock, D. J., Hoffbrand, A. V., Mollin, D. L., and Booth, C. C. (1967). A study of proximal and distal intestinal structure and absorptive function in idiopathic steatorrhoea. Quart. J. Med., 36, 425-444.

Swift, J. A., and Marsh, M. N. (1968). Scanning electron microscopy of rat intestinal microvilli. Lancet, 2,915.

Trier. J. S. (1963) Studies on the small intestinal crypt epithelium 1 -The fine structure of the crypt epithelium of the proximal small intestine of fasting humans. J. Cell. Biol., 18, 599-620. 